\title{
Research Paper: The Effect of Eight Weeks Resistance Training With and Without Vascular Occlusion on Growth Hormone, and Insulin-Like Growth Factor in Male
}

\author{
Kazem Sabri' ${ }^{1}$, Mehrdad Fathi ${ }^{2}$, Keyvan Hejazi ${ }^{3 *}$
}

1. Department of Physical Education, Faculty of Humanities \& Basic Sciences, Bojnourd Branch, Islamic Azad University, Bojnord, Iran. 2. Department of Physical Education and Sports Sciences, Faculty of Sport Sciences, Ferdowsi University of Mashhad, Mashhad, Iran. 3. Department of Physical Education, Toos Institute of Higher Education, Mashhad, Iran.

Funding: See Page 155

(c) Copyright: The Author(s)

\section{Article info:}

Received: 25 Jan 2017

Accepted: 15 Jun 2017

Available Online: 01 Oct 2017

Keywords:

Vascular occlusion, Resistance training, Growth hormone, Insulinlike growth factor
Cittation Sabri K, Fathi M, Hejazi K. The Effect of Eight Weeks Resistance Training With and Without Vascular Occlusion on Growth Hormone, and Insulin-Like Growth Factor in Male. Physical Treatments. 2017; 7(3):149-156. http:// dx.doi.org/10.32598/ptj.7.3.149

http://dx.doi.org/10.32598/ptj.7.3.149

\begin{abstract}
A B S T R A C T
Purpose: The present study was conducted to investigate the effect of 8 weeks resistance training with and without vascular occlusion on physical fitness indexes, growth hormone, and Insulin-like Growth Factor 1 (IGF-1) in male judokas.

Methods: In this quasi-experimental study, 20 male judokas were divided into two groups: 1. Traditional resistance training along with judo training without blood vascular occlusion $(n=10)$; and 2. Resistance training group along with judo training with blood vascular occlusion $(n=10)$. Resistance training schedule included 3 sessions per week, each session lasting 45 to 60 minutes for 8 weeks. The comparison of means within and between groups was done by paired sample $t$ test and ANCOVA test, respectively. All statistical analyses were performed with SPSS V. 20. Results were significant at $\mathrm{P} \leq 0.05$.
\end{abstract}

Results: Results showed that cardio respiratory endurance, anaerobic power, speed, agility, muscular endurance and power, changed significantly in both resistance groups with and without vascular occlusion. Growth hormone and insulin-like factor growth changed significantly. Concerning intergroup means changes in variables of cardio respiratory endurance $(\mathrm{P}=0.03)$, anaerobic ability $(\mathrm{P}=0.02)$, speed $(\mathrm{P}=0.03)$, agility $(\mathrm{P}=0.03)$, muscular endurance $(\mathrm{P}=0.007)$, power $(\mathrm{P}=0.01)$, growth hormone $(\mathrm{P}=0.01)$ and insulin-like growth factor $(\mathrm{P}=0.03)$, there was a significant change between two groups of resistance training with vascular occlusion and without vascular occlusion.

Conclusion: Eight weeks of resistance training with and without vascular occlusion, improved motorphysical fitness indexes and increased growth hormone and insulin-like growth factor in male judokas.

\footnotetext{
* Corresponding Author:

Keyvan Hejazi, PhD

Address: Department of Physical Education, Toos Institute of Higher Education, Mashhad, Iran.

Phone: +98 (51) 36063044

E-mail: keyvanhejazi@gmail.com
} 


\section{Introduction}

$\mathbf{R}$

esistance exercises are a strong incentive for increasing protein synthesis of muscles and accordingly the muscle volume [1]. The different methods of this exercise follow two main goals: increase in maximum strength and muscular hypertrophy $[2,3]$. Findings show that hard strength training may result in severe muscular and tissue injuries. Therefore researchers try to find innovating, safe, and effective methods for maintaining and developing muscular strength for a wide range of people [1].

In light of that, they proposed a kind of exercise called resistance training with vascular occlusion. In this method, the blood flow input of active muscle in training is limited or stopped by closing an elastic rubber band around the proximal part of arm and thigh [4]. The intensity of these trainings is usually between $20 \%$ and $30 \%$ of maximum repetition (almost equal to people routine level of activity intensity). Therefore individuals with different physical features can tolerate it. Some studies show that strength training with vascular occlusion bears the same advantages and even more of traditional strength training [5].

Studies show that change in hormones secretion due to exercise, as the main factor in protein synthesis, occurs after strength trainings and leads to positive adaptations in the structure of skeletal muscles [6]. Growth hormone and insulin-like growth factor 1 are among anabolic hormones affecting muscular growth and hypertrophy [7]. Growth hormone is one of the most important anabolic hormones which increases muscular growth and hypertrophy both directly by facilitating the transition of amino acids into cells, and indirectly by producing intermediary protein in liver and other cells in the name of insulin-like growth factor or somatomidin C [8].

It has been shown that low-intensity exercises with limited blood flow is an effective method for the quick increase of strength and hypertrophy, besides muscular injuries are not seen much in these exercises [9]. In this regard, Libardi et al. [10] studied endurance training in 30- to 40 -minute sessions with $50 \%$ to $80 \%$ of oxygen consumption two days per week for 12 weeks, and strength training of feet press done by 25 volunteers in 4 sets and 10 repetitions with $70 \%$ to $80 \% 1$ RM (oneRep Max) and 60 seconds of rest between sets for two days per week.
They concluded that there is a significant difference between control group and training group with regard to strength, aerobic ability and the size of quadriceps cross-section area; however, there was no significant difference between the two training groups. Segal et al. [11] by studying 4 weeks of exercise with vascular occlusion and 30\% 1RM reported the improvement of quadriceps muscular strength in 42 men and better recuperation in their knees.

Although many research studies have been conducted in this field, different results have been reported due to various samples and training programs used. Considering the contradictory results, further research in this field seems necessary. Also, no research has been done in this area and on this specific sport. Regarding judo nature which requires physical fitness such as agility, speed, muscular strength, and taking into account the fact that muscular strength is considered as the basic elements for success in sport as well as daily practices, we attempted to compare the effect of 8 weeks of endurance training with and without blood flow occlusion on physical fitness indexes and growth factors as well as insulin-like growth factor in male judokas in order to find out whether there is a difference between two methods of endurance training (with and without blood occlusion).

\section{Materials and Methods}

This is a quasi-experimental study which was conducted on two experimental groups with pretest and posttest. The sample included 20 male judokas which were selected through available and purposeful selective sampling. First the subjects were identified based on study methodology. The inclusion criteria included 4 years of continuous judo training, no history of drug use, or smoking, with complete physical and mental health. The subjects participated in the study voluntarily and signed the consent form.

Then the subjects were randomly divided into two groups: 1. Traditional strength training plus judo training without blood vascular occlusion; and 2. Strength training plus judo training with blood vascular occlusion. In this study in order to measure body composition, subjects' height was measured by Seca height gauge (made in Germany) with $5 \mathrm{~mm}$ precision, hips and waist with band meter (Japan) with $5 \mathrm{~mm}$ precision, weight with $100 \mathrm{~g}$ precision. Body mass index was calculated by dividing body weight over height square in terms of meter. Based on the power value of $80 \%, \alpha=0.05$, and variation of means as 2.5 units, a sample size of 10.97 was obtained. 


\section{Blood sampling}

In this study, blood samples were first taken from the subjects' left hand veins in sitting position as well as in resting position 24 hours before the trainings and 48 hours after the last training session. All the samples were taken between $8 \mathrm{AM}$ to $9 \mathrm{AM}$ in the laboratory. To measure the value of Insulin-like hormone growth (IGF-1), Mediagnost kit (made in Germany) was used with Elisa method and sensitivity of $0.1 \mathrm{ng} / \mathrm{mL}$. The growth hormone was also measured by Padtan Elm kit (made in Iran) with sensitivity of $0.1 \mathrm{ng} / \mathrm{mL}$ and with Elisa Reader GDV machine (made in Italy).

\section{Study procedure}

After recording the subjects' general condition and making sure about their not suffering with diseases such as high blood pressure, diabetes, obesity and atherosclerosis, they were provided with information about the nature of the study as well as the potential dangers. Then the subjects according to the schedule participated in motor and physical fitness tests in order to measure their cardiorespiratory endurance (1600 m running), anaerobic power (vertical jumping), speed (36 $\mathrm{m}$ or 40 yards), agility ( $4 \times 9)$, muscular endurance $(30 \%$ test of one maximum repetition) and power (long jump).

\section{Training plan}

The first experimental group (traditional endurance training group) were taking part in 10 minutes warm-up, the main program and 10 minutes cool down. The main program included 3 set squats, knees extension (front of thigh) and foot hug in 4 sets (for 8 weeks, 3 sessions per week and each session 50 minutes); rest time between each station was 4 minutes [12]. To keep the overload principle, each week $20 \%$ of $1 \mathrm{RM}$ was added to the training pressure [13].

\section{Strength training protocol with vascular occlusion (Kaatsu)}

The plan of the second experimental group was the same as the first one in 4 sets, while their feet were closed by cuff (cuff was opened in the end of stations and closed in the beginning) [14]. Till the training there was $30 \%$ of $1 \mathrm{RM}$. The first set had 30 repetitions and the next three sets 15 repetitions. The rest time between sets was 1 minute and 4 minutes between stations. For training sessions with blood vascular occlusion, before training blood flow was limited for 30 seconds by means of $120 \mathrm{~mm} \mathrm{Hg}$ cuff and then was freed for 10 seconds.
Then $20 \mathrm{~mm}$ Hg was added to the previous pressure and blood flow was limited and then set free for the same period of time. This was repeated till the pressure reached the target [15]. To be sure of the danger of blood pressure during and after training, the subjects' blood pressure was checked regularly. Cuff pressure was considered to be between 160 to $240 \mathrm{~mm}$ Hg. First the pressure was $160 \mathrm{~mm} \mathrm{Hg}$ and each two weeks $20 \mathrm{~mm} \mathrm{Hg}$ was added till it reached to $240 \mathrm{~mm} \mathrm{Hg} \mathrm{[15].}$

\section{Statistical analysis}

The obtained data were analyzed by SPSS version 20 . After confirming the normality of data distribution by Shapiro-Wilk test and variances homogeneity by Levene's test, within and between means comparison were done by paired sample $t$ test and ANCOVA test, respectively. For all test results, the significance level was considered to be $\mathrm{P}<0.05$.

\section{Results}

The subjects' characteristics in this study are presented in Table 1. Based on the findings presented in Table 2, there is a significant difference among these variables between strength training groups with and without blood vascular occlusion regarding cardio respiratory endurance $(\mathrm{P}=0.001)$, anaerobic power $(\mathrm{P}=0.001)$, speed $(\mathrm{P}=0.001)$, agility $(\mathrm{P}=0.001)$, muscular endurance $(\mathrm{P}=0.001)$ and ability $(\mathrm{P}=0.001)$.

According to the findings presented in Table 2, independent $t$ results showed that changes of means in both training groups with and without blood vascular occlusion indicating a significant change in the variables of cardio respiratory endurance $(\mathrm{P}=0.03)$, anaerobic power $(\mathrm{P}=0.002)$, speed $(\mathrm{P}=0.03)$, muscular endurance $(\mathrm{P}=0.001)$ and ability $(\mathrm{P}=0.006)$. Based on the findings presented in Table 3, there was a significant increase in the variables of growth hormone $(\mathrm{P}=0.01)$ and insulinlike growth factor $(\mathrm{P}=0.03)$. The changes of means among groups in growth hormone and insulin-like growth factor were significant.

\section{Discussion}

According to the study results, there is a significant difference between strength training with and without blood vascular occlusion concerning cardio respiratory endurance of male judokas. The results are consistent with the findings of Anabestani et al. and Hosseini et al. studies [16, 17]. Anabestani et al. [17] examined the effect of combined exercises with and without vascu- 
Table 1. The characteristics of the study subjects

\begin{tabular}{|c|c|c|c|c|c|c|c|}
\hline \multirow{3}{*}{ Variables } & \multirow{3}{*}{ Group(s)* } & \multicolumn{2}{|c|}{ Mean $\pm S D$} & \multicolumn{4}{|c|}{ Variations } \\
\hline & & \multirow{2}{*}{ Pre-Test } & \multirow{2}{*}{ Post-Test } & \multicolumn{2}{|c|}{ Within Groups } & \multicolumn{2}{|c|}{ Between Groups } \\
\hline & & & & $t$ & $\mathbf{P}$ & $\mathbf{F}$ & $\mathbf{P}$ \\
\hline \multirow{2}{*}{ Age (y) } & (1) & $18.00 \pm 0.81$ & - & - & - & \multirow{2}{*}{ - } & \multirow{2}{*}{ - } \\
\hline & (2) & $17.80 \pm 0.76$ & - & - & - & & \\
\hline \multirow{2}{*}{ Height (m) } & (1) & $1.76 \pm 1.87$ & - & - & - & \multirow{2}{*}{ - } & \multirow{2}{*}{ - } \\
\hline & (2) & $1.78 \pm 1.70$ & - & - & - & & \\
\hline \multirow{2}{*}{ Weight (kg) } & (1) & $66.44 \pm 3.84$ & $65.85 \pm 3.60$ & 3.23 & $0.01 \ddagger$ & \multirow{2}{*}{0.92} & \multirow{2}{*}{0.36} \\
\hline & (2) & $67.18 \pm 5.02$ & $66.80 \pm 5.32$ & 2.82 & $0.02 \ddagger$ & & \\
\hline \multirow{2}{*}{ BMI $\left(\mathrm{kg} / \mathrm{m}^{2}\right)$} & (1) & $21.39 \pm 1.17$ & $21.20 \pm 1.10$ & 3.20 & $0.001 \ddagger$ & \multirow{2}{*}{0.95} & \multirow{2}{*}{0.35} \\
\hline & (2) & $21.14 \pm 1.40$ & $21.02 \pm 1.49$ & 2.18 & $0.002 \ddagger$ & & \\
\hline
\end{tabular}

\section{PHYSICAL TREA $\mid$ MENTS}

‡: The mean difference is significant at the 0.05 level; *: (1): Strength training plus judo training with blood vascular occlusion; (2): Traditional strength training plus judo traininwithout blood vascular occlusion

lar obstruction on selected factors of physical fitness in postmenopausal women. They concluded that in two experimental groups and in comparison with the control group, muscle strength, muscular endurance and cardiopulmonary endurance significantly increased, but there was no significant difference between the two training groups.
Low-intensity, combined exercises with vascular obstruction have the same effect as traditional highintensity combined exercises on muscle strength and endurance, and cardio-respiratory endurance in postmenopausal women. Hosseini et al. [16] focused on young girls to compare resistance exercises with obstruction and without obstruction. They concluded that strength and muscular endurance increased, but no

Table 2. The mean, standard deviation of fitness indexes records among different groups of male judokas

\begin{tabular}{|c|c|c|c|c|c|c|c|c|}
\hline \multirow{3}{*}{ Variables } & \multirow{3}{*}{ Group(s)* } & \multicolumn{2}{|c|}{ Mean $\pm S D$} & \multicolumn{5}{|c|}{ Variations } \\
\hline & & \multirow{2}{*}{ Pre-Test } & \multirow{2}{*}{ Post-Test } & \multicolumn{2}{|c|}{ Within Groups } & \multicolumn{2}{|c|}{ Between Groups } & \multirow{2}{*}{ Effect Size } \\
\hline & & & & $\mathbf{t}$ & $\mathbf{P}$ & $\mathbf{F}$ & $\mathbf{P}$ & \\
\hline \multirow{2}{*}{$\begin{array}{l}\text { Cardiorespiratory endurance } \\
\qquad(\mathrm{min})\end{array}$} & (1) & $6.28 \pm 0.05$ & $6.13 \pm 0.09$ & 8.29 & $0.01 \neq$ & \multirow{2}{*}{1.58} & \multirow{2}{*}{$0.03 \ddagger$} & \multirow{2}{*}{0.017} \\
\hline & (2) & $6.29 \pm 0.04$ & $6.20 \pm 0.09$ & 4.83 & $0.01 \ddagger$ & & & \\
\hline \multirow{2}{*}{ Anaerobic power $(\mathrm{cm})$} & (1) & $41.00 \pm 5.27$ & $46.10 \pm 4.58$ & -9.00 & $0.01 \ddagger$ & \multirow{2}{*}{2.63} & \multirow{2}{*}{$0.02 \ddagger$} & \multirow[b]{2}{*}{0.24} \\
\hline & (2) & $38.10 \pm 6.21$ & $40.60 \pm 6.74$ & -0.55 & $0.01 \ddagger$ & & & \\
\hline \multirow[b]{2}{*}{ Speed (s) } & (1) & $5.92 \pm 0.34$ & $5.50 \pm 0.30$ & 3.43 & $0.07 \ddagger$ & \multirow[b]{2}{*}{8.67} & \multirow[b]{2}{*}{$0.03 \ddagger$} & \multirow[b]{2}{*}{0.39} \\
\hline & (2) & $6.14 \pm 0.30$ & $6.04 \pm 0.31$ & 3.89 & $0.01 \ddagger$ & & & \\
\hline \multirow{2}{*}{ Agility (s) } & (1) & $9.41 \pm 0.09$ & $9.26 \pm 0.15$ & 3.63 & $0.01 \ddagger$ & \multirow{2}{*}{0.04} & \multirow{2}{*}{$0.03 \ddagger$} & \multirow{2}{*}{0.24} \\
\hline & (2) & $9.37 \pm 0.11$ & $9.33 \pm 0.11$ & 7.93 & $0.01 \ddagger$ & & & \\
\hline \multirow{2}{*}{ Muscular endurance (1RM) } & (1) & $53.60 \pm 4.40$ & $69.80 \pm 11.47$ & -4.82 & $0.01 \ddagger$ & \multirow{2}{*}{1.42} & \multirow{2}{*}{$0.01 \ddagger$} & \multirow{2}{*}{0.36} \\
\hline & (2) & $56.10 \pm 5.79$ & $60.50 \pm 5.91$ & -6.68 & $0.01 \ddagger$ & & & \\
\hline \multirow{2}{*}{ Power (m) } & (1) & $2.43 \pm 0.08$ & $2.50 \pm 0.08$ & -6.70 & $0.01 \ddagger$ & \multirow{2}{*}{2.74} & \multirow{2}{*}{$0.01 \ddagger$} & \multirow{2}{*}{0.24} \\
\hline & & & $241+011$ & -3.26 & & & & \\
\hline
\end{tabular}

¥: The mean difference is significant at the 0.05 level; *: (1): Strength training plus judo training with blood vascular occlusion; (2): Traditional strength training plus judo training without blood vascular occlusion 
Table 3. The mean, standard deviation of growth hormone and Insulin-like growth factor judokas

\begin{tabular}{|c|c|c|c|c|c|c|c|c|}
\hline \multirow{3}{*}{ Variables } & \multirow{3}{*}{ Group(s)* } & \multicolumn{2}{|c|}{ Mean $\pm S D$} & \multicolumn{5}{|c|}{ Variations } \\
\hline & & \multirow{2}{*}{ Pre-Test } & \multirow{2}{*}{ Post-Test } & \multicolumn{2}{|c|}{ Within Groups } & \multicolumn{2}{|c|}{ Between Groups } & \multirow{2}{*}{ Effect Size } \\
\hline & & & & $\mathbf{t}$ & $\mathbf{P}$ & $\mathbf{F}$ & $\mathbf{P}$ & \\
\hline \multirow{2}{*}{$\begin{array}{l}\text { Growth hormone } \\
(\mathrm{ng} / \mathrm{mL})\end{array}$} & (1) & $1.79 \pm 0.35$ & $2.69 \pm 0.31$ & -0.67 & $0.01 \ddagger$ & \multirow{2}{*}{30.71} & \multirow{2}{*}{$0.01 \ddagger$} & \multirow{2}{*}{0.65} \\
\hline & (2) & $1.46 \pm 0.20$ & $1.65 \pm 0.34$ & -3.26 & $0.01 \ddagger$ & & & \\
\hline \multirow{2}{*}{$\begin{array}{l}\text { Insulin-like growth } \\
\text { factor (ng/mL) }\end{array}$} & (1) & $211.90 \pm 5.78$ & $218.80 \pm 6.30$ & -4.86 & $0.01 \ddagger$ & \multirow{2}{*}{1.03} & \multirow{2}{*}{$0.03 \ddagger$} & \multirow{2}{*}{0.26} \\
\hline & (2) & $211.00 \pm 6.10$ & $214.30 \pm 6.12$ & -12.11 & $0.01 \ddagger$ & & & \\
\hline
\end{tabular}

¥: The mean difference is significant at the 0.05 level; *: (1): Strength training plus judo training with blood vascular occlusion; (2): Traditional strength training plus judo training without blood vascular occlusion

change in maximal oxygen consumption was observed. Aerobic exercises can improve aerobic ability by increasing oxidative enzymes, capillary density and glycogen content in muscles as well as increasing stroke volume and decreasing heart stroke [18].

Aerobic training with vascular occlusion in low intensity trainings such as walking, can increase muscular strength and hypertrophy [15]. During walking training on treadmill with occlusion, oxygen consumption increases significantly and a higher rate of heart stroke has been observed in training with occlusion rather than without occlusion [15]. The new training method with occlusion seems to decrease the amount of blood input which decreases stroke volume and increases heart stroke while cardiac output is kept constant [19].

Oxygen consumption increase during training with occlusion may be due to increase in arterial and venous blood oxygen $\left(\mathrm{a}-\mathrm{VO}_{2}\right)$, while cardiac output during training with occlusion is the same as without occlusion. In Takarada et al. study [20], one of the proposed mechanisms for improving endurance in training with occlusion, was increasing blood vessels in the trained muscles. Also studies show that while muscles experience limited blood flow, both hypoxia and metabolites accumulation play an important role in capillary proliferation of muscles [9]. Endurance improvement in a strained muscle in ischemic conditions can increase blood supply and afterward lead to oxygen emancipation increase [21].

The results of the present study show a significant difference between the effect of 8 weeks of traditional and Kaatsu training (with limited blood flow) on muscular strength. Also this training course has led to a significant increase in the level of muscular strength of the lower part of body in both experimental groups. Strength increase after sport training may be due to cellular and molecular changes in central nervous systems of mo- tor units, muscle-nerve connecting point, and involved systems in sarcoplasmic network, mitochondria or in the contractile proteins themselves. Therefore various variables such as hormonal changes as well as type, duration and intensity of training can determine the main target of changes [22, 23]. In strength training, muscular straining and hormonal changes, activate waterfall pathways of genes and protein synthesis, that in addition to metabolic changes, lead to structural changes especially in the thick side of myosin fiber, which finally results in hypertrophy [24].

Studies show that the more intensive strength training leads to more increase in strength. Brochu et al. [25] in their study concluded that endurance training leads to a significant increase in the strength of lower part of body $(23 \%)$. One of the main reasons of strength increase after sport activity is the volume increase of muscle due to the proliferation of fibers, fibrils or connective tissues. Also more motor units are involved during the exercise [26].

To researchers, one of the mechanisms of strength increase in Kaatsu group can be muscular-nervous mechanism as well as metabolic and periodic conditions change [27]. It is generally believed that strength training in hypoxic conditions accumulates metabolic materials (lactic acid, ADP), involves more motor units and increases electric activity of muscles. This can be due to the following reasons: using muscles of body's lower part compared to the upper part. Studies show that strength increase in lower parts (bigger muscles) is more tangible compared to the upper parts [28].

In some studies, in addition to muscular-nervous adaptations, hormone adaptations have been also studied. These studies show that training in muscular hypoxia condition accumulates metabolites and accordingly increases GH and IGF density in a higher amount compared to traditional training, and this is followed by 
muscular growth and strength increase [29]. Therefore the increase in GH and IGF-1 hormones with other metabolic by-products can be a reason for strength increase in training groups, especially the group with vascular occlusion. Also strength increase due to training with vascular occlusion can be caused by xanthine oxidase levels and satellite cells activation, and finally increase of muscle cross-sectional area and muscular hypertrophy [21].

It is believed, however, that in low intensity strength training, muscular endurance increases, and if this low intensity is accompanied by vascular occlusion it leads to strength and muscle size increase. In this study hypertrophy and muscular cross-section area was not observed, but according to the tangible increase of muscular strength, probably the cross-section area of quadriceps muscle and hamstring has increased. Therefore in further studies the observation of cross-section area and muscle volume, besides functional changes, should be considered.

According to the findings of this study, after 8 weeks of traditional and Kaatsu strength training (with blood flow vascular occlusion), the muscular endurance of the lower part of body increased significantly. Also findings showed a significant difference between the effect of 8 weeks of traditional and Kaatsu strength training. The high increase in muscular endurance in Kaatsu group can be associated with the increase in muscular strength and number of high frequencies of trainings, because studies show that strength and endurance increase have a direct relationship.

Among the mechanisms influential in improving endurance one can refer to increase in type 2 fibers, muscular glycogen storage, and the improvement of glycolytic capacity of type 2 fibers [30]. Studies show that increase in muscular endurance is initially due to muscle adaptation through increase in oxidative energy metabolism, acid buffering capacity, and endurance against fatigue. Training with low intensity and blockage which is followed by outside pressure on the upper part of thigh, presses veins and arterial blood flow during muscle training considerably and leads to hypoxia and metabolites accumulation, both of which play important roles in increasing muscular endurance capacity. Studies show that hypoxia is strongly related to the growth of blood veins [12].

Among other findings of this study, one can refer to the increase in feet explosive strength level after 8 weeks of Kaatsu and traditional endurance training (with limited blood flow). In interpreting the increase of feet explosive strength due to training, sufficient training time and mus- cular strength have been mentioned. Because the training had sufficient time and there was tangible increase in muscular strength, the increase of feet explosive strength was expected. Generally the studies done in the field of strength trainings effect on explosive strength, have suggested hypertrophy as the reason for the improvement of feet explosive strength function [31]. In the present study, the hypertrophy of thigh muscles were not considered; however, in such training programs thigh muscles would face hypertrophy.

According to the present study, one can mention the significant increase in the level of growth hormone and insulin-like growth factor after 8 weeks of Kaatsu and traditional endurance training (with limited blood flow). The results of this study are consistent with the findings of Fujita et al. Takarada et al. and Abe et al. [29, 32, 33]. Following a Kaatsu resistance training session, Fujita et al. [32] observed that growth hormone increased significantly after 10 minutes, but in the group without restriction, there was no change in growth hormone.

After performing Kaatsu Resistance Exercise, Takarada et al. [29] reported significant increase in the concentration of growth hormone after exercise compared to that at rest time [33]. Abe et al. [33] reported that Kaatsu exercises for 24 weeks (Two training sessions in a week with low intensity exercises) increased IGF-1 levels by $24 \%$. Hormones can be secreted due to inside and outside pressure on the body. Adaptation with intensive training can increase the secretion of many hormones. It has been shown that sport training leads to hormone secretion and any pressure which is followed by more muscular sarcolemma stimulation, increases anabolic hormone levels, especially growth hormone [34].

Generally doing low intensity training with limited blood flow leads to growth hormone increase as much as high intensity training. Findings show that high intensity training increases growth hormone considerably [35]. Stimulation for hormone response is through afferent feedback, in a way that less mechanical stress is followed by less hormonal response. Also increase in the level of training intensity enhances intracellular forces. On the other hand, difference in the training intensity and volume is effective on muscular oxygen recovery after training and delayed responses for oxygen reconstruction, are effective on growth hormone response [36]

Also anaerobic trainings may stimulate growth hormone more. In other words, limited blood flow decreases oxygen delivery and finally is followed by lactate formation that accumulates in the targeted muscle and lim- 
ited blood flows avoid the transition of lactates to liver and other tissues. Therefore, lactate accumulation may increase the secretion of growth hormone [37]. Low intensity strength training with vascular occlusion has a similar effect to traditional high intensity strength training on physical fitness indexes and growth hormone and insulin-like growth factor in male judokas. Therefore strength training with vascular occlusion and low intensity can probably replace high intensity strength training in these people.

\section{Ethical Considerations}

\section{Compliance with ethical guidelines}

The steps for tests were approved by the Ethics Committee at the Faculty of Humanities \& Basic Sciences, Bojnourd Branch, Islamic Azad University under the code No. 252426.

\section{Funding}

This work was supported by Bojnord Branch, Islamic Azad University.

\section{Conflict of interest}

The authors declared no conflict of interest.

\section{Acknowledgments}

The authors would like to thank the subjects who participated in this study.

\section{References}

[1] Abe T, Sakamaki M, Fujita S, Ozaki H, Sugaya M, Sato Y, et al. Effects of low-intensity walk training with restricted leg blood flow on muscle strength and aerobic capacity in older adults. Journal of Geriatric Physical Therapy. 2010; 33(1):34-40. [PMID]

[2] Kargarfard M, Amiri E, Moradian K. [The comparison of four resistance training protocols on level of human growth hormone secretion in beginner male athletes (Persian)]. Journal of Isfahan Medical School. 2010; 28(108):1-10.

[3] Cezar MA, De Sá CA, Corralo VDS, Copatti SL, dos Santos GAG, Grigoletto MES . Effects of exercise training with blood flow restriction on blood pressure in medicated hypertensive patients. Motriz: Revista de Educação Física. 2016; 22(2):9-17. [DOI:10.1590/S1980-6574201600020002]

[4] Park SY, Kwak YS, Harveson A, Weavil JC, Seo KE. Low intensity resistance exercise training with blood flow re- striction: Insight into cardiovascular function, and skeletal muscle hypertrophy in humans. The Korean Journal of Physiology \& Pharmacology. 2015; 19(3):191-96. [DOI:10.4196/ kjpp.2015.19.3.191] [PMID] [PMCID]

[5] Suga T, Okita K, Morita N, Yokota T, Hirabayashi K, Horiuchi $\mathrm{M}$, et al. Dose effect on intramuscular metabolic stress during low-intensity resistance exercise with blood flow restriction. Journal of Applied Physiology. 2010; 108(6):156367. [DOI:10.1152/japplphysiol.00504.2009] [PMID]

[6] Sheffield-Moore M. Urban RJ. An overview of the endocrinology of skeletal muscle. Trends in Endocrinology \& Metabolism. 2004; 15(3):110-5. [DOI:10.1016/j. tem.2004.02.009] [PMID]

[7] Kraemer WJ, Aguilera BA, Terada M, Newton RU, Lynch JM, Rosendaal G. Responses of IGF-I to endogenous increases in growth hormone after heavy-resistance exercise. Journal of Applied Physiology. 1995; 79(4):1310-5. [DOI:10.1152/ jappl.1995.79.4.1310] [PMID]

[8] Häkkinen K, Pakarinen A, Kraemer WJ, Häkkinen A, Valkeinen $\mathrm{H}$, Alen M. Selective muscle hypertrophy, changes in EMG and force, and serum hormones during strength training in older women. Journal of Applied Physiology, 2001. 91(2):569-80. [DOI:10.1152/jappl.2001.91.2.569] [PMID]

[9] Loenneke JP, Pujol TJ. The use of occlusion training to produce muscle hypertrophy. Strength \& Conditioning Journal. 2009; 31(3):77-84. [DOI:10.1519/SSC.0b013e3181a5a352]

[10] Libardi CA, Chacon-Mikahil MPT, Cavaglieri CR, Tricoli V, Roschel H, Vechin FC, et al. Effect of concurrent training with blood flow restriction in the elderly. International Journal of Sports Medicine. 2015; 36(05):395-9. [DOI:10.1055/s-0034-1390496] [PMID]

[11] Segal NA, Williams GN, Williams MC, Wallace RB, Mikesky AE. Efficacy of blood flow-restricted, low-load resistance training in women with risk factors for symptomatic knee osteoarthritis. Physical Medicine and Rehabilitation. 2015; 7(4):376-84. [DOI:10.1016/j.pmrj.2014.09.014] [PMID] [PMCID]

[12] Takarada Y, Sato Y, Ishii N. Effects of resistance exercise combined with vascular occlusion on muscle function in athletes. European Journal of Applied Physiology. 2002; 86(4):308-14. [DOI:10.1007/s00421-001-0561-5] [PMID]

[13] Yasuda T, Fukumura K, Fukuda T, Iida H, Imuta H, Sato Y, et al. Effects of low-intensity, elastic band resistance exercise combined with blood flow restriction on muscle activation. Scandinavian Journal of Medicine \& Science in Sports. 2014; 24(1):55-61. [DOI:10.1111/j.1600-0838.2012.01489.x] [PMID]

[14] Wilk KE, Voight ML, Keirns MA, Gambetta V, Andrews JR, Dillman CJ. Stretch-shortening drills for the upper extremities: theory and clinical application. Journal of Orthopaedic \& Sports Physical Therapy. 1993; 17(5):225-39. [DOI:10.2519/ jospt.1993.17.5.225] [PMID]

[15] Abe T, Beekley MD, Hinata S, Koizumi K, Sato Y. Day-today change in muscle strength and MRI-measured skeletal muscle size during 7 days KAATSU resistance training: A case study. International Journal of KAATSU Training Research. 2005; 1(2):71-6. [DOI:10.3806/ijktr.1.71]

[16] Hosseini A, Sharifi A. [A comparison of the effect of traditional resistance training with resistance training with vas- 
cular occlusion on muscular function and cardiovas-cular endurance in young females (Persian)]. Journal of Sport Biosciences. 2012; 4(10):95-114.

[17] Anabestani M, Hosseini-Kakhk A, Hamedinia MR. [Comparison of combined training with and without vascular occlusion on selected physical fitness components in postmenopausal women (Persian)]. Sport Physiology. 2014; 6(21):123-36

[18] Sundberg CJ. Exercise and training during graded leg ischaemia in healthy man with special reference to effects on skeletal muscle. Acta Physiologica: The Scandinavian Physiological Society. 1994; 615:1-50. [PMID]

[19] Takano H, Morita T, Iida H, Asada KI, Kato M, Uno K, et al. Hemodynamic and hormonal responses to a short-term lowintensity resistance exercise with the reduction of muscle blood flow. European Journal of Applied Physiology. 2005; 95(1):6573. [DOI:10.1007/s00421-005-1389-1] [PMID]

[20] Takarada Y, Ishii N. Effects of low-intensity resistance exercise with short interset rest period on muscular function in middleaged women. Journal of Strength \& Conditioning Research. 2002; 16(1):123-8. [DOI:10.1519/00124278-200202000-00019]

[21] Patterson SD, Ferguson RA. Increase in calf post-occlusive blood flow and strength following short-term resistance exercise training with blood flow restriction in young women. European Journal of Applied Physiology. 2010; 108(5):1025-33. [DOI:10.1007/s00421-009-1309-x] [PMID]

[22] Van Praagh E. Pediatric anaerobic performance. Stanningley: Human Kinetics Publishers; 1998.

[23] Tipton CM. ACSM's advanced exercise physiology. Philadelphia: Lippincott Williams \& Wilkins; 2006.

[24] Surakka J. Power-type strength training in middle-aged men and women. Toronto: National Public Health Institute; 2005.

[25] Brochu M, Savage P, Lee M, Dee J, Cress ME, Poehlman ET, et al. Effects of resistance training on physical function in older disabled women with coronary heart disease. Journal of Applied Physiology. 2002; 92(2):672-8. [DOI:10.1152/japplphysiol.00804.2001] [PMID]

[26] Folland JP, Irish CS, Roberts JC, Tarr JE, Jones DA. Fatigue is not a necessary stimulus for strength gains during resistance training. British Journal of Sports Medicine. 2002; 36(5):370-3. [DOI:10.1136/bjsm.36.5.370] [PMID] [PMCID]

[27] Karabulut M, Abe T, Sato Y, Bemben MG. The effects of low-intensity resistance training with vascular restriction on leg muscle strength in older men. European Journal of Applied Physiology. 2010; 108(1):147-155. [DOI:10.1007/s00421-009-1204-5] [PMID]

[28] Kraemer WJ, Adams K, Cafarelli E, Newton RU. American College of Sports Medicine position stand: Progression models in resistance training for healthy adults. Medicine and Science in Sports and Exercise. 2002; 34(2):364-80. [DOI:10.1097/00005768200202000-00027] [PMID]

[29] Takarada Y, Nakamura Y, Aruga S, Onda T, Miyazaki S, Miyazaki N. Rapid increase in plasma growth hormone after low-intensity resistance exercise with vascular occlusion Journal of Applied Physiology. 2000; 88(1):61-5. [DOI:10.1152/ jappl.2000.88.1.61] [PMID]

[30] Coffey VG, Hawley JA. The molecular bases of training adaptation. Sports Medicine. 2007; 37(9):737-63. [DOI:10.2165/00007256-200737090-00001] [PMID]
[31] Glowacki SP, Martin SE, Maurer A, Baek W, Gren JS, Crous $\mathrm{SF}$. Effects of resistance, endurance, and concurrent exercise on training outcomes in men. Medicine and Science in Sports and Exercise. 2004; 36(12): 2119-27. [DOI:10.1249/01. MSS.0000147629.74832.52] [PMID]

[32] Fujita T, Brechue WF, Kurita K, Sato Y, Abe T. Increased muscle volume and strength following six days of low-intensity resistance training with restricted muscle blood flow. International Journal of KAATSU Training Research. 2008; 4(1):1-8. [DOI:10.3806/ijktr.4.1]

[33] Abe T, Yasuda T, Midorikawa T, Sato Y, Kearns CF, Inoue K, et al. Skeletal muscle size and circulating IGF-1 are increased after two weeks of twice daily "KAATSU" resistance training. International Journal of KAATSU Training Research. 2005; 1(1):6-12. [DOI:10.3806/ijktr.1.6]

[34] Marks DM, Kravitz L. Hormones and resistance exercise.The Journal of Strength \& Conditioning Research. 2000; 14(2):200-27.

[35] Wideman L, Weltman JY, Hartman ML, Veldhuis JD, Weltman A. Growth hormone release during acute and chronic aerobic and resistance exercise. Sports Medicine. 2002; 32(15):987-1004. [DOI:10.2165/00007256-200232150-00003] [PMID]

[36] Hoffman JR, Im J, Rundell KW, Kang J, Nioka Sh, Spering BA, et al. Effect of muscle oxygenation during resistance exercise on anabolic hormone response. Medicine and Science in Sports and Exercise. 2003; 35(11):1929-34. [DOI:10.1249/01. MSS.0000093613.30362.DF] [PMID]

[37] Reeves GV, Kraemer RR, Hollander DB, Clavier J, Thomas C, Francois $\mathrm{M}$, et al. Comparison of hormone responses following light resistance exercise with partial vascular occlusion and moderately difficult resistance exercise without occlusion. Journal of Applied Physiology. 2006; 101(6):1616-22. [DOI:10.1152/ japplphysiol.00440.2006] [PMID] 